Dr. K.B. Greenland

Staff Specialist

Department of Anaesthesia and Perioperative Medicine

Royal Brisbane and Royal Women's Hospital

Butterfield Street, Herston

Brisbane, Qld., Australia. 4006.

\title{
Comparison of the Williams Airway Intubator and the Intubating Laryngeal Mask for fibreoptic orotracheal intubation in anaesthetised patients
}

O. Kam ${ }^{1}$, K.B. Greenland ${ }^{2}$ and M.G. Irwin ${ }^{3}$

1 Anaesthetic Trainee, Prince of Wales Hospital, Sha Tin, Kowloon, Hong Kong

2 Staff Anaesthetist Department of Anaesthesia and Perioperative Medicine, Royal Brisbane \& Women's Hospital, Butterfield St., Herston, Brisbane, Queensland, Australia. 3 Associate Professor and Head, Department of Anaesthesiology, University of Hong Kong, Room 424 K Block, Queen Mary Hospital, Pokfulam Road, Hong Kong

Correspondence to: Dr. K.B. Greenland

e-mail: french9a@yahoo.co.uk 
Intubating patients with a fibreoptic bronchoscope after induction of anaesthesia is an important method of securing an airway when difficulty in intubation has occurred. Specific airways have been devised to assist the anaesthetist during fibreoptic intubation to allow a clear view in front of the bronchoscope as it passes from the mouth, through the glottis and into the trachea. These airways have been broadly classified as dedicated and non-dedicated.

A 'dedicated airway'(1) has been defined as 'an upper airway device dedicated to the maintenance of airway patency while other major airway interventions are anticipated or in progress - the device should be compatible with spontaneous and controlled ventilation'. Of these, the laryngeal mask is the first choice when the patient is difficult to intubate and especially if ventilation with a face mask is also challenging (2). The Intubating Larnygeal Mask in particular, provides the best ability to intubate in these circumstances.

The non-dedicated airways include the Ovassapian Fibreoptic Intubating Airway, Berman Intubating Airway (Vital Signs, Totowa, New Jersey, USA) and the Williams Airway Intubator (Williams Airway Intubator Ltd, Calgary, USA). Studies have shown that of these airways the Williams $(3,4)$ appears to function as the best conduit for fibreoptic intubation in anaesthetised patients. Oropharyngeal airways like these have particular advantages over 'dedicated' airways where mouth opening is limited, cervical spine movement is undesirable, and when larger tracheal tubes are preferred. In addition, they are relatively easy to insert and cheap compared to the more complex 'dedicated' airways.

It is the intention of this study to compare the Williams Airway Intubator with the Intubating Larnygeal Mask as conduits for fibreoptic intubation in anaesthetised patients and to critically appraise their suitability in this situation.

\section{Methods}

Approval for the study will be obtained by the local institutional review board. Informed consent will be obtained from sixty adult patients of American Society of Anesthesiologists grading (ASA) 1- 2 who are presenting for elective surgery requiring tracheal intubation. Those with upper airway disease, a past history of 
difficult tracheal intubation, or the following signs of possible difficult tracheal intubation (a modified Mallampati score of 3 or 4 , mouth opening $<3 \mathrm{~cm}$, thyromental distance $<4 \mathrm{~cm}$, or limited neck movement) will be excluded from the study. To avoid skill variability and maintain consistency of results, one experienced specialist anaesthetist (O.K.) will be chosen to perform all the assessments and intubations in the selected patients. Oxygen saturation will be maintained above $95 \%$ at all times during the procedure.

All patients will be placed supine and the head will be positioned in the classic 'sniffing position' that the operator feels is optimal for intubation. Routine noninvasive monitoring (ECG, non-invasive blood pressure measurement, pulse oximetry and end tidal $\mathrm{CO}_{2}$ analysis) will be utilised and after pre-oxygenation for $3 \mathrm{~min}$, the patient will receive intravenous induction of anaesthesia with fentanyl 1-1.5 $\mu \mathrm{g} . \mathrm{kg}$ ${ }^{1}$ and propofol 2-3 mg. $\mathrm{kg}^{-1}$. Muscle paralysis will then be achieved with rocuronium $0.5 \mathrm{mg} \cdot \mathrm{kg}^{-1}$. Either the Williams Airway Intubator or the Intubating Larnygeal Mask Airway (ILMA) will then be inserted into the mouth in random order by the operator performing the assessment. The length of airway will be chosen to ensure that it is slightly greater than the distance from the angle of the mouth to the angle of the mandible. It will be impossible to blind the operator to the airway being used as she will need to observe the airway while she performs the procedure. The patient's lungs will be ventilated by bag and facemask with $100 \%$ oxygen and $2-3 \%$ sevoflurane. A bronchoscope (Olympus LF-GP, Olympus America Inc., USA) will be pre-loaded with a 7.0-mm endotracheal tube (Portex Ltd, Hythe, Kent, UK) in the case of the Williams Airway and the LMA Fastrach ETT when using theILMA. The bronchoscope tip will be level with the distal end of the $7.0 \mathrm{~mm}$ tracheal tube and the LMA Fastrach ETT so that in the case of the ILMA, the Fastrach tube will raise the epiglottic elevator bar and the assessment may be completed. The tracheal tubes will be well lubricated with K-Y® Brand Jelly (Johnson \& Johnson Inc.,USA).

At this time, an assistant will apply chin lift and ensure the airway is in the midline to optimise positioning and placement. The bronchoscopic view of the glottis via the airway will be formally assessed once the bronchoscope has just passed the distal end of the airway. The time taken to view the glottis will be recorded as the time from initially inserting the bronchoscope at the proximal opening of the airway until the tip 
of the bronchoscope is positioned at the level of the vocal cords. The bronchoscopy times will recorded by a second assistant using a stop watch.

The first airway will then be removed, the other airway inserted and the assessment will be repeated. Following this second assessment the bronchoscope will be advanced into the trachea to a level just above the carina and the tracheal tube railroaded over it, through the airway and into the trachea. The number of attempts and any difficulties advancing the tracheal tube over the bronchoscope and through the trachea will be noted. The bronchoscope will then be removed and the patients' lungs ventilated via the tracheal tube.

We will use a previously validated classification for the bronchoscopic view (5)(Table 1) in an attempt to clarify the sites of obstruction that may lead to bronchoscopic difficulties. Ease of intubation will be assessed using the scoring system proposed by Jones et al. (6)(Table 2). The anaesthetist performing both the assessment and intubation will use these same classification systems. 
Table 1: Fibreoptic laryngeal grade and airway patency.

Grade 4 - vocal cords only seen (function of the airway adequate)

Grade 3 - vocal cords and posterior epiglottis seen (function of the airway adequate)

Grade 2 - vocal cords and anterior epiglottis seen (function of the airway adequate)

Grade 1 - vocal cords not seen (function of the airway adequate)

Grade 0 - vocal cords not seen (function of the airway inadequate).

Table 2: Classification of the ease of intubation through the Williams Airway Intubator.

Grade 0 No hold-up encountered

Grade 1 Hold-up on initial attempt, relieved by withdrawal and rotation of tube through $90^{\circ}$ anti-clockwise

Grade 2 Hold-up on initial attempt requiring more than one manipulation of the tube, alteration in head or neck position or external manipulation 


\section{References:}

1. Charters P, O'Sullivan E. The "dedicated airway": a review of the concept and an update of current practice. Anaesthesia 1999;54:778-786.

2. Caplan R, Benumof J, Berry F, Blitt C, Bode R, Cheney F, et al. Practice Guidelines for Management of the Difficult Airway: An Updated Report by the American Society of Anesthesiologists Task Force on Management of the Difficult Airway. Anesthesiology 2003;98:1269-1277.

3. Greenland K, Lam M, Irwin M. Comparison of the Williams Airway Intubator and Ovassapian Fibreoptic Intubating Airway for fibreoptic orotracheal intubation. Anaesthesia 2004;59:173-176.

4. Greenland K, Irwin M. The Williams Airway Intubator, the Ovassapian Airway and the Berman Airway as upper airway conduits for fibreoptic bronchoscopy in patients with difficult airways. Current Opinion in Anaesthesiology 2004;17:505510.

5. Brimacombe J, Berry A. A proposed fibre-optic scoring system to standardise the assessment of laryngeal mask airway position. Anesthesia and Analgesia 1993;76:457.

6. Jones H, Pearce A, Moore P. Fibreoptic intubation. Influence of tracheal tube tip design. Anaesthesia 1993;48:672-4. 